\title{
New Exploration on the Educational Mode Reform of Humanistic Quality of Medical Students
}

\author{
Mi Feng \\ Qiqihar Medical University \\ Qiqihar Heilongjiang Province 161000
}

\author{
Song Yaoxin* Corresponding author \\ Qiqihar Medical University \\ Qiqihar Heilongjiang Province 161000
}

\begin{abstract}
In this paper, combined with the requirements of education reform and the student's actual situation and proposed to reform and explore problems in the educational mode of humanistic quality of the medical students, feasible countermeasures and suggestions of the improvement of humanities education quality are put forward from the perspective of college students' humanistic quality education way and function analysis. By theoretical analysis, the core issues are studied to find the existing problems and explore the problems of humanistic education existing in educational idea, teaching staff, curriculum planning, the school spirit and culture and infrastructure construction, etc. and these problems are solved properly.
\end{abstract}

Keywords-Medical students; Humanistic quality; Education mode; reform

Humanistic quality has a great impact on the overall development of medical students, and it has become a consensus that medical colleges should pay more attention to the education of humanistic quality. We should pay more attention to humanistic education and improve the efficiency of education, and give full play to the important role of humanistic classroom teaching. By continuously improving teaching methods and creating a good atmosphere of classroom teaching, students can get the maximum degree of humanistic influence in the limited class hours. [1]

\section{THE METHODS AND FUNCTION ANALYSIS OF MEDICAL STUDENTS' HUMANISTIC QUALITY EDUCATION}

Under the background of unceasingly deepening educational reform at present, medical colleges and universities are necessary to further explore ways of humanistic quality education of medical students from the perspective of discipline knowledge, cultural concept and humanistic thought and humanistic spirit. Through exploring the way of humanity quality education, fully understanding the role of humanity quality education, we will further improve the medical students knowledge structure, to better complete the medical students' humanistic quality education of each work, make the humanities knowledge and professionalism.

\section{A. Education of specific subject knowledge}

The foundation of the humanities is thick and deep. It can help people to understand the nature of human history and understand modern and future society. The humanities are not limited by its major, it is widely applied, and it pays attention to cultivating generalists. The broad scope of the humanities makes it possible for all majors to have an open vision and wide range of knowledge, and to improve the taste of art, literature and aesthetics other than professional knowledge. The development of The Times calls for strengthening the knowledge of the humanities, and the sustainable development calls for high-quality talents with knowledge of the humanities.

It is urgent to strengthen the humanities knowledge and reflect the all-round development in morality, intelligence, physique, art and labor in higher and deeper level for the all-round development of college students, which is an important initiative to fully implement the Party's educational policy under the new situation. By strengthening teaching humanities knowledge, cultivating humanistic campus cultural atmosphere, organizing all kinds of social practice activities, students can serve society in their studies and practice and their humanistic quality are improved.

\section{B. Improve students' advanced cultural concepts}

Culture plays an important role in humanistic thought level. The way people observe, weigh, decide, plan, practice and summarize is a kind of concept activity, which are the characteristics of objectivity, logicality, profundity and generalization. To get things done and done right, you must have a clear and correct idea to improve your living standards and quality of life.

Humanistic knowledge contains humanistic thought, which has a strong ideological character, rich national color and distinctive personality traits compared with scientific thought. The core of humanistic thought is the basic cultural idea. Everyone's mission and responsibility is to develop all of their abilities in a comprehensive way, including the ability to think.

The concept of advanced culture permeates humanistic thinking, advocates people's love of life, respects for others, personal liberation and equality of people is the link between advanced cultural concepts and humanistic thought.

\section{The cultivation of humanistic spirit of medical students}

As the core position in the humanistic education, humanistic spirit is the foundation of world outlook and values of the humanities, which is the most important embodiment of humanistic thought and humanistic approach. The essence of human culture and civilization is the humanist spirit. The national spirit and he time spirit is the concrete manifestation of the humanistic spirit. The university education must promote the humanistic spirit which needs to be strengthened to adapt to the development and progress of the times for the development of colleges and universities.

This article is the research production of Heilongjiang Provincial Philosophy and Social Sciences Research and Planning Project "Highe Medical College medical humanities quality training model reform research", approval number: 17EDD180 
Humanism is the humanistic spirit which runs through the thoughts and words of ideal and faith, values, religious beliefs, aesthetic temperament and interest. Humanistic spirit reflects the essence of human nature. It is the highest aim of education to promote the spirit of people's level. The humanistic spirit is the continuous development, perfection and expansion of human beings, the development of personality and personality, and the pursuit of human destiny.

College students in the new century should have both professional knowledge and sound personality, which should have both scientific knowledge and humanistic spirit. It is necessary to realize the importance of humanistic quality to college students and promote the development of university students' humanistic education in the era of knowledge economy.[2]

\section{THE MODEL AND SUGGESTION OF HUMANISTIC QUALITY EDUCATION IN MEDICAL COLLEGES AND UNIVERSITIES}

In order to improve the humanistic quality of medical students, we should make medical students not only rich in knowledge, but also talented people in the spirit world through the humanistic quality education. Combined with the requirements of education reform and the actual condition of students, some suggestions and exploration on educational mode of humanistic quality are put forward to help current medical colleges and universities carry out educational work of humanistic quality, thus obtaining good effect.

\section{A. We will open a wide range of elective courses for humanities and social sciences, and strengthen the cultivation of humanistic spirit of college students}

Humanistic quality has a great impact on college students' all-round development, and education, which should attach importance to humanistic quality, has become the consensus. It is important to give full play to the function of education and improve the efficiency of education. By continuously improving teaching methods and creating a good atmosphere of classroom teaching, students can get the maximum degree of humanistic influence in the limited class hours. In terms of humanistic curriculum, the university should not only pay attention to humanistic education value of curriculum Settings, but also pay much attention to the cultivation of students' humanistic spirit, the cultural background of the proposed rights issue related to the professional courses and a coaching classes, in order to let students understand the cultural and historical background of the related to the major such as the humanities knowledge and enhance the connotation of the professional culture, stimulate students' interest in learning, which in turn can also help students to better learn professional class.

\section{B. The teaching of specialized courses should combine the education of humanistic quality and improve the humanistic quality of professional teachers}

The teacher should make the humanities education for students, first to strengthen their humanistic qualities, to inherit the excellent traditional culture, and to learn the essence of multiculturalism. In order to change the traditional way of thinking, we should try our best to help students' growth and progress. Teachers should strive to establish their humanistic spirit and encourage ideological freedom in the teaching process. Education students think, explore and innovate independently. Teachers should not only teach humanistic knowledge, but also cultivate students' inner humanistic spirit and guide, infect and edify students. The humanistic quality of teachers is the core of the teaching level, and the depth of humanistic quality is related to the professional level of teachers.

\section{To correctly handle the relationship between humanistic quality and professional quality education, improve curriculum setting}

Humanistic education and education are not opposites. Instead, education is a great help for education, which is a professional education. Meanwhile, education can't leave professional education alone. In today's world characterized by the rapid development of science and technology, higher education has a strong professional, students should find a balance between the humanities and the professional disciplines, not only to learn professional knowledge, but also to learn cultural knowledge, improve the breadth and depth of knowledge, to achieve mastery through a comprehensive study between different professional and cultural. Rights in the process of teaching and appropriate practice strengthen the exchange between humanistic education and professional education, emphasize on students with humanistic care, and guide the students to pursue the value of life and the scientific truth. Optimizing the humanities education curriculum, literature, art, ethics, history and culture of course can increase properly proportion, to form a widening knowledge, strengthen the basic knowledge of curriculum system, to adopt flexible and varied teaching methods, curriculum Settings to cultivate students to pursue all-round development and to improve the personal qualities of the humanistic spirit.

\section{We will strengthen infrastructure construction and improve the teaching resources of the humanities curriculum}

How to improve the hardware and software conditions of personnel training and strengthen the university students' humanistic quality education is a practical problem for every college and university. It is very important to provide the necessary infrastructure for teaching. The campus culture with rich connotation can be built from the perspective of resource integration. We need to share resources among colleges and optimize them to cultivate excellent talents with strong comprehensive strength. In the aspect of hardware, it requires to ensure the teaching areas and supporting facilities. In the aspect of software, it requires to strengthen teachers' team construction, change teachers' teaching concept and improve teaching skill, especially teachers themselves, the quality of which is directly related to the quality of personnel training. In the school teaching resources based on development, on the basis of setting accords with the practice of the school development goals, and actively strive for resources of other universities, resource sharing in the maximum play to the role of the excellent education resources. In the classroom on the basis of the textbook, starting from the teaching actual need, complement select material, let the students learn to analyze and solve problems in the practice of teaching, improve the learning interest and knowledge. 


\section{E. Strengthen campus culture construction and create a good atmosphere of campus culture}

Campus culture is a special cultural phenomenon that is different from ordinary culture, which is the external manifestation of school spirit and school spirit. The cultural construction of campus directly influences the humanistic quality of college students and the quality of school education. It is necessary to recognize the significance of campus culture construction from the core values of socialism. Forms of the marker in the campus, is a reflection of the campus material culture, the forms of the vulgar, rows of buildings, beautiful crest, gaily sculpture, the school magazine, newspaper, etc. are an important part of campus culture.

Actively carry out the school wind construction, dig deeply into the school's historical tradition, vigorously carry out the school spirit, the school discipline construction, and build the campus atmosphere that has its own characteristic. We will strengthen students' management and strengthen students' education, so as to create a vigorous and innovative study style. For example, various and colorful campus cultural activities are organized in a variety of organized or irregular organizations, which include education, education, education, and education, etc., into campus cultural activities. Let the students be inspired in the activity, body and mind are enriched.

\section{F. Improve college students' mind and cultivate the moral sentiment of college students}

Everyone is used to learn problems and solve problems with their own special and habitual way of thinking. However, as the environment changes, the knowledge is rich, the experience increases, the cognition changes, the mental model of people is also changing constantly. The mental model is not invariable, and the imperfect mental model can be continuously improved in the life practice and gradually changed. The perfect mental model can help college students to choose their career. In order to promote their own development, college students should constantly improve their mental models to meet the needs of society. [3-4]

When training students, colleges should cultivate students with a holistic point of view, change original thinking inertia and strengthen system consciousness. When knowing antecedents and consequence, students should have global consciousness. And their abilities on analysis and solving complicated problems can be cultivated. College students should have a good mentality, knowledge, and cultivation of qualified compound talents. Therefore, to provide students with the mind education is a teaching content that colleges cannot ignore.

We should have a high sense of mission and responsibility, and make campus civilization construction and students' mental development the starting point of the education of the university. And focus on the targeted morality to develop education, regulate students' daily behaviors, and arouse the awareness of public morality.

\section{CONCLUSIONS:}

As an important part of national cultural construction, humanistic quality training must adapt to meet the demands of the rapid development of society, so that students' spirit can be developed in a positive direction. The lack of humanistic quality for college students shows that colleges and universities need to explore deeply the underlying reasons behind these phenomena. These aspects such as humanistic curriculum, humanities and professional education share, content, evaluation mechanism, humanistic quality education college students themselves and the external factors should be analyzed in a reasonable manner. From the perspective of the method of cultivation, the cultivation of the specific subject knowledge will be treated as the foundation of humanistic quality education and the essence of advanced cultural concept will be absorbed. Meanwhile, by using appropriate humanistic method of cognition and practice, the humanistic spirit will be placed in an important position.

\section{REFERENCES}

[1] M.Li Taiping. Science education and human education, People's publishing house, 2010. (In Chinese)

[2] M.Zhang Daqing. Chinese Medical Humanities Education, Peking University Medical Press, 2006. (In Chinese)

[3] M.Ma Cugen. Research on humanistic quality in education of higher medicine, People's health press, 2004. (In Chinese)

[4] M.Du Shizhong. Humanistic Education, Jiangsu education press, 1999. (In Chinese) 